Grbavac,H.D.Democracia deliberativa y suspensión del juicio a prueba: una reflexión sobre sus posibles conexiones. Derecho y Ciencias Sociales. Octubre 2018. N Pgs 75-92 ISNN 1852-2971. Instituto de Cultura Jurídica

\title{
Democracia deliberativa y suspensión del juicio a prueba: una reflexión sobre sus posibles conexiones
}

Deliberative democracy and diversion: a reflection on its posible conections

\section{Hernán Darío Grbavac}

\section{Resumen}

Con el presente trabajo se reflexionará sobre las posibles conexiones entre la democracia deliberativa y el instituto de la suspensión del juicio a prueba.

Se explicitará cómo el Derecho Penal de una comunidad democrática debería considerar y aplicar el castigo penal y de qué manera esa concepción proyectaría determinadas consecuencias sobre la manera de interpretar el instituto de la suspensión del juicio a prueba y algunas de las cuestiones problemáticas que se presentan en su actual régimen legal.

El trabajo permitirá, además, hacer visibles las profundas relaciones existentes entre las teorías de la pena, el régimen de la acción penal y la suspensión del juicio a prueba, todo en el marco del paradigma de democrático-deliberativo.

Palabras Clave: Democracia deliberativa; Suspensión del Juicio a Prueba; Pena; Acción Penal.

\begin{abstract}
With this paper, I will reflect on the possible connections between the deliberative democracy and the diversion.

I will explain how the Criminal Law of a democratic community should consider and apply the punishment and how this conception would project certain consequences on the way in which it the institute of the diversion should be interpreted and some of the problems that are presented in its current legal regime.

The paper, also, will, make visible the deep relationship between theories of punishment, the regime of criminal action and the diversion, all within the framework of the democracy-deliberative paradigm.
\end{abstract}

Keywords: Deliberative Democracy ; Diversion ; Punishment ; Criminal Action.

\footnotetext{
- Abogado (UNNE). Profesor en Ciencias Jurídicas y Especialista en Derecho Penal (U de Cuenca del Plata) .Becario Doctoral del Conicet (Corrientes). Adjunto de Derecho Penal II (U de Cuenca del Plata) y JTP de Metodología de la ciencia Jurídica (UNNE). hernangrbavac@hotmail.com
} 
Grbavac,H.D.Democracia deliberativa y suspensión del juicio a prueba: una reflexión sobre sus posibles conexiones. Derecho y Ciencias Sociales. Octubre 2018. N Pgs 75-92 ISNN 1852-2971. Instituto de Cultura Jurídica

\section{Democracia deliberativa y suspensión del juicio a prueba: una reflexión sobre sus posibles conexiones.}

\section{Hernán Darío Grbavac}

\section{Introducción.}

Con el presente trabajo reflexionaremos acerca de las posibles conexiones entre democracia deliberativa y suspensión del juicio a prueba. En esa línea, nos detendremos a analizar las eventuales implicancias que una concepción deliberativa del Derecho Penal podría proyectar sobre el instituto mencionado y cómo ello repercutiría en el modo de entender el texto de los arts. 76 y siguientes del Código Penal, que determinan su actual régimen legal.

La suspensión del juicio a prueba, al permitir la suspensión de un proceso penal iniciado contra un imputado, se encuentra estrechamente conectada con los presupuestos que deben estar presentes para imponer o, en este caso, no imponer, a un sujeto una sanción penal. Esos presupuestos no pueden estar divorciados de lo que una comunidad democrática puede exigirle a sus ciudadanos, en tanto agentes morales con capacidad de deliberar entre sí y actuar conforme a razones morales. Así, deviene necesario reflexionar sobre la teoría de la pena que podría ser compatible con un Derecho Penal deliberativo.

En síntesis, esbozaremos una argumentación sobre la suspensión del juicio a prueba entendida ésta como una derivación del régimen de la acción penal, el que, a su vez, se encuentra determinado por la teoría de la pena que se adopte, la que, por su parte, es parasitaria del enfoque deliberativo propuesto.

\section{Desarrollo.}

\section{1. La suspensión del juicio a prueba en la Argentina.}

El instituto de la suspensión del juicio a prueba fue incorporado al Derecho argentino por la ley $24.316^{1}$, que agregó los arts. 76 bis, 76 ter y 76 quater al Código Penal ${ }^{2}$. La figura permite que un acusado, bajo ciertas condiciones, logre el dictado de una resolución por la cual se suspende la acción penal y, con ella, el juicio iniciado en su contra, por un cierto tiempo transcurrido el cual y, en la medida en que el imputado cumpla con los deberes

\footnotetext{
${ }^{1}$ B.O.: 19/5/1994.

${ }^{2}$ A su vez, la ley 26.735 (B. O. 28/12/2011) agregó el último párrafo al art. 76 bis; en tanto, la ley 27.147 (B. O.: 18/6/2015) modificó el art. 76, insertándolo dentro del Título que regula la suspensión del juicio a prueba, y el art. 59, en el que se añadió la referencia a la extinción de la acción penal una vez cumplidas las condiciones y el plazo fijados en la suspensión del juicio a prueba (inc. 7).
} 
Grbavac,H.D.Democracia deliberativa y suspensión del juicio a prueba: una reflexión sobre sus posibles conexiones. Derecho y Ciencias Sociales. Octubre 2018. N Pgs 75-92 ISNN 1852-2971. Instituto de Cultura Jurídica

impuestos y con las reglas de conducta fijadas, se extingue la acción penal (art. 59 inc. 7 y art. 76 cuarto párrafo, Cód. Penal), debiéndose dictar su sobreseimiento por el hecho en cuestión.

Ahora bien, la suspensión del juicio a prueba, ¿es un derecho del imputado a evitar el juicio?, o simplemente ¿se trata de un criterio de oportunidad expresamente contenido en la ley y gobernado por presupuestos distintos de los que regulan el reconocimiento de un derecho? En esta línea, ¿cuál es la posible relación que existiría con una teoría de la pena?

Las respuestas a dichas preguntas podrían resolver los problemas generados por la confusa redacción del art. 76 bis del Código Penal. A título de ejemplo: i) la solicitud de un imputado de que se aplique el instituto, particularmente en los supuestos de los dos primeros párrafos, ¿debería ser vinculante para los órganos del Estado?; ii) la eventual oposición de la víctima, ¿sería relevante para resolver la aplicación (o no) del instituto?; iii) ¿cómo debe interpretarse la exclusión de la figura para los delitos reprimidos con pena de inhabilitación?, es decir, ¿abarca a los delitos que sólo se encuentran conminados con pena de inhabilitación?, o ¿se extiende también para las ofensas, como los delitos culposos, que tienen prevista la pena de inhabilitación en forma conjunta?; iv) ¿qué consecuencias tendrían ciertos tratados internacionales de derechos humanos suscriptos por el Estado argentino (v. gr., la Convención de Belem do Para en lo referido a los delitos cometidos en contextos de violencia de género) para la aplicación del instituto?

\section{2. La suspensión del juicio a prueba, ¿un derecho del imputado?}

Un sector de la doctrina argentina entiende que la suspensión del juicio a prueba es un derecho del imputado. Así, v. gr., Bovino (2006), luego de recordar cuáles serían las razones del instituto (limitar el poder punitivo del Estado racionalizando la respuesta penal sólo ante los casos que fuesen imprescindibles en términos de resocialización; atender a los intereses de la víctima; combatir el colapso del sistema judicial), considera que la figura es un derecho del imputado a evitar la persecución penal y, eventualmente, la condena. En ese marco, "la tarea del tribunal se limita a controlar la legalidad de la solicitud, el texto legal no le concede discreción alguna que le permita rechazar el pedido por motivos de oportunidad" (2006: 173). En tanto, Molero (1998) afirma que la figura es un derecho de los ciudadanos que persigue un fin rehabilitador "[evitando] los posibles efectos desocializantes de las penas" y "la estigmatización del individuo [imputado]” (1998: 1348 y 1350). De igual modo, Arocena sostiene que la figura "constituye un verdadero derecho del imputado, el que, en cuanto tal puede ser o no ejercido por su titular" (2010: 95), lo que 
Grbavac,H.D.Democracia deliberativa y suspensión del juicio a prueba: una reflexión sobre sus posibles conexiones. Derecho y Ciencias Sociales. Octubre 2018. N Pgs 75-92 ISNN 1852-2971. Instituto de Cultura Jurídica

"significa que, ejercido que fuera tal derecho, pesa sobre el tribunal un correlativo deber de disponer la suspensión, cuando concurrieren los presupuestos de procedencia establecidos en la ley" (2010: 96).

Ahora bien, concebir la suspensión del juicio a prueba como un derecho del imputado trae consigo una serie de consecuencias. En primer término, implica considerar al instituto desde la óptica de las garantías constitucionales de un imputado sometido a proceso. En esa línea, la solicitud de aplicación de la figura constituiría una manifestación del derecho de defensa en juicio y, así como un imputado puede abstenerse de declarar sin que nadie pueda obligarlo a actuar de otro modo, también podría solicitar la aplicación de la figura que, por ser una derivación de derecho a la defensa en juicio, no podría serle negada por el Estado $^{3}$. Cada sujeto sometido a proceso tendría así el derecho de evitar el juicio en su contra, tal como lo sostienen los autores citados y tal como lo entendíamos nosotros en un trabajo anterior (Molero \& Grbavac, 2013). Incluso, así lo consideró la Corte Suprema en la causa "Padula y otros" (CSJN, Fallos: 320:2451, 11/11/1997), cuando expresó que el procesado tiene "derecho (...) a poner fin a la acción y evitar la imposición de una pena" (consid. $5^{\circ}$ ).

En ese marco, afirmar que el imputado tiene un derecho a evitar el juicio, produciendo eventualmente la extinción de la acción penal, bloquea cualquier pretensión estatal en contrario. Como diría Dworkin (1993 [1977]), tener un derecho implica contar con una "carta de triunfo" en el sentido de que aquél no puede ser vulnerado o no reconocido en virtud de pretensiones o medidas que persigan beneficios de utilidad en términos agregativos: "la perspectiva de logros utilitarios no puede justificar que se impida a un hombre hacer lo que tiene derecho de hacer" (Dworkin: 1993 [1977]: 288) ${ }^{4}$. La suspensión del juicio a prueba sería así una "restricción centrada en la persona" (Braithwaite \& Petti, 2015 [1990]: 47) que se le impone a la justicia penal y que, como tal, "debe cumplirse sin importar cuáles sean las consecuencias", ya que "esa garantía es simplemente la otra cara de la restricción" (Braithwaite \& Pettit, 2015 [1990]: 48 y 47). Así, el derecho del imputado a evitar el juicio no podría serle denegado a partir de razones de "seguridad pública”.

Sin embargo, podría decirse que esta fundamentación supone que la pena a la que se enfrenta un acusado fue considerada a partir de criterios prevencionistas y que, por lo

\footnotetext{
${ }^{3}$ En la medida en que, desde luego, fueran observadas sus condiciones formales de admisibilidad.

${ }^{4}$ Así, reconocer que "los ciudadanos tienen derecho a la libertad de expresión debe implicar que estaría mal que el Gobierno les impidiese usar de ella, aun cuando el Gobierno crea que lo que han de decir causará más mal que bien" (Dworkin: 1993 [1977]: 284).
} 
Grbavac,H.D.Democracia deliberativa y suspensión del juicio a prueba: una reflexión sobre sus posibles conexiones. Derecho y Ciencias Sociales. Octubre 2018. No Pgs 75-92 ISNN 1852-2971. Instituto de Cultura Jurídica

tanto, el derecho del imputado podría ser superado por otro derecho, v. gr., el derecho de la víctima del delito (lo que se explicaría desde una concepción retribucionista de la pena). No obstante, este argumento enfrenta dos problemas. Por un lado, una teoría retributiva de la pena es incompatible con un Derecho penal respetuoso de los principios liberales de la responsabilidad penal ${ }^{5}$. Pero, además, ello implicaría concebir el derecho de la víctima como más importante que el derecho de defensa en juicio del acusado, lo que no dejaría de ser contraintuitivo ya que, con ello, se generaría un estado de cosas en el que quedaría sin su nota fundamental la noción de garantía constitucional ${ }^{6}$. Los derechos no se subordinan o limitan por consideraciones de bienestar general sino a la inversa (Dworkin, 1993 [1977]), ya que su función consiste en atrincherar ciertos intereses individuales bloqueando la posibilidad de que ellos fuesen dejados de lado (Nino, 2007 [1989] y 2003 [1997]) ${ }^{7}$

No obstante, reflexionar sobre las implicancias que se desprenderían de concebir a la suspensión del juicio a prueba como un derecho, permiten comprender el problema. Si aquélla es un derecho y si, como tal, éste no puede serle negado al imputado que solicita su aplicación, se estaría generando una suerte de "cheque en blanco" o "impunidad a la carta" cada ocho años ${ }^{8}$. Así cualquier sujeto podría ocasionar dolosamente, v. gr., una lesión grave $^{9}$ (art. 90, Cód. Penal) o gravísima ${ }^{10}$ (art. 91, Cód. Penal) o causar tales lesiones culposamente (art. 94, Cód. Penal) o una privación agravada de la libertad bajo ciertos supuestos $^{11}$ (art. 142, Cód. Penal), o una amenaza -con o sin armas- (art. 149 bis, Cód. Penal), según la tesis sentada en "Acosta" (CSJN, Fallos: 331:858, 23/4/2008) y "Norverto" (CSJN, N. 326. XLI. RHE, 23/4/2008]) ${ }^{12}$. Las consecuencias serían gravemente contraintuitivas, ya que parecería que se promovería o, cuanto menos, toleraría

\footnotetext{
${ }^{5}$ En virtud de que la retribución se expresa a través del "reproche" y éste sólo puede tener como objeto las actitudes, intenciones o motivos que tuvo el agente al momento de actuar. El retribucionismo conduciría así a una versión subjetivista extrema del injusto penal, que pasa por alto el principio de lesividad penal. Véase Nino (2013).

${ }^{6}$ Éste es, a nuestro juicio, uno de los mayores problemas del sistema acusatorio-adversarial de procedimiento penal.

${ }^{7}$ Una crítica determinante de la que es pasible una justificación utilitarista de la democracia reside justamente en que aquélla no deja ningún margen para que los derechos puedan actuar como contrapeso ante las decisiones mayoritarias tomadas en términos agregativos (Nino, 2003 [1997]).

${ }^{8}$ El término que debe transcurrir desde que expira la primera suspensión para que pueda volver a solicitarse la aplicación del instituto (art. 76 quinto párrafo, Cód. Penal).

${ }^{9}$ Consistente, v. gr., en sacar un ojo, extirpar un riñón, o deformar el rostro de otro.

${ }^{10}$ Es decir, v. gr., dejar inválido a otro, amputarle un brazo o una pierna, castrarlo o dejarlo ciego.

${ }^{11}$ Si la privación de la libertad, v. gr., se extiende por más de un mes (inc. 5) o se comete con violencias o amenazas (inc. 1).

${ }^{12}$ Por los que se admite la concesión del instituto cuando sea posible la condena de ejecución condicional, con independencia del máximo de la pena que el/los delito/s tuviera/n previsto en abstracto.
} 
Grbavac,H.D.Democracia deliberativa y suspensión del juicio a prueba: una reflexión sobre sus posibles conexiones. Derecho y Ciencias Sociales. Octubre 2018. No Pgs 75-92 ISNN 1852-2971. Instituto de Cultura Jurídica

una situación de impunidad ${ }^{13}$, horadándose la confianza de los ciudadanos en las ventajas del sistema democrático de gobierno. Se resentiría aún más ${ }^{14}$ la conciencia de que es valioso cumplir con la ley y que los órganos públicos deben estar comprometidos en la lucha contra la impunidad ${ }^{15}$.

Un posible contraargumento podría decir que el imputado tiene derecho a solicitar el instituto pero que la concesión del mismo no depende de su persona sino de la evaluación que realice el juez. Sin embargo, este razonamiento no agregaría nada a la discusión (al fin y al cabo, nadie discute que el imputado puede pedir su aplicación), reduciendo tal requerimiento a una petición vacía ante las autoridades.

Por otro lado, entender la suspensión del juicio a prueba como un derecho -cuya solicitud ataría de manos al Estado- presupone una consideración negativa del juicio (la continuidad de un proceso con la consecuente aproximación a una sentencia condenatoria siempre sería negativo para el sujeto investigado). Podría incluso decirse que, muchas veces, esta continuidad es per se un argumento en contra del juicio penal, toda vez que quien se encuentra imputado, en situación de incertidumbre, estaría, en cierto modo, suspendido, "fuera del mundo", no pudiendo proyectar su propia vida. Sin embargo, ello no debería necesariamente ser así. No pensamos aquí en los supuestos de extensión de un proceso con las connotaciones que fueran graficadas por Kafka (1967 [1925]) ni estamos reflexionado a partir de una descripción de los juicios penales vigentes en nuestras sociedades. El juicio penal caracterizado en $\mathrm{El}$ Proceso es un juicio impuesto a un individuo por una colectividad que aplasta su individualidad, como consecuencia de un modelo de sociedad determinada; es un juicio, en el que pueden verse magnificadas una variedad de rasgos de nuestros juicios, que trata al acusado burocráticamente y en el que la ley se le presenta a

\footnotetext{
${ }^{13}$ Podría contraargumentarse diciendo que, al tener que ofrecer el imputado “...hacerse cargo de la reparación del daño en la medida de lo posible...” (art. 76 bis tercer párrafo, Cód. Penal), la suspensión del juicio a prueba no implica impunidad ni genera una suerte de "cheque en blanco", ya que quien solicita su aplicación debe ofrecer un resarcimiento. Sin embargo, este argumento no podría dejar de reconocer que entender la figura como un derecho significa instaurar una especie de "abolicionismo penal" para ciertas ofensas cada cierto tiempo. El mensaje de ese "abolicionismo" sería lo que causaría el sentimiento de impunidad ya que los ciudadanos -incluyendo los que se beneficiarían con esa concepción del institutotraducirían el "derecho a la suspensión del juicio a prueba" como el "derecho a estar exentos de responder penalmente por las consecuencias de los delitos que se sospecha habrían cometido". La suspensión del juicio a prueba no bloquea sólo una eventual condena, antes bien, impide el juicio; en ese marco, el sobreseimiento del imputado determina que el hecho (motivo de investigación penal) no existió. En esta línea, véase lo que dicen Braithwaite \& Pettit (2015 [1990]) sobre los efectos perniciosos de una regla que, p. ej., impida el procesamiento de delitos leves o de quienes cometan un delito por primera vez.

${ }^{14}$ Sobre la anomia en la sociedad argentina, véase Nino (1992).

${ }^{15}$ Distinto es el caso de la institución de la condena condicional, ya que en este caso hay una condena, esto es, tiene lugar la desaprobación por parte de la comunidad política, a través de su administración de justicia, del acto delictivo que la acusación logró acreditar. Lo mismo sucede con la institución de la probation anglosajona. Sostener lo contrario, implicaría confundir "no impunidad" con "prisión efectiva".
} 
Grbavac,H.D.Democracia deliberativa y suspensión del juicio a prueba: una reflexión sobre sus posibles conexiones. Derecho y Ciencias Sociales. Octubre 2018. N Pgs 75-92 ISNN 1852-2971. Instituto de Cultura Jurídica

aquél como algo inentendible e inaccesible al punto que el protagonista es juzgado por un hecho y por un delito que desconoce. Es cierto también que los juicios penales actuales, con su lenguaje encriptado, con su excesivo rigor formal, muchas veces con la ausencia de una auténtica deliberación entre las partes y con la exclusión de la ciudadanía reunida en jurados, también se encuentran lejos del ideal deliberativo que funda el presente trabajo. Pero a nada de ello nos estamos refiriendo cuando pensamos en el juicio penal desde una concepción deliberativa.

Además, considerar el juicio de un modo negativo presupone aislar al individuo de su comunidad. De otro modo, el juicio penal, visto desde una concepción deliberativa del Derecho, es el espacio o foro público a través del cual la comunidad llama a los sujetos sospechados de haber cometido un delito a rendir cuentas y a expresar las razones que consideren valederas a sus intereses (Duff, 2015a y 2015b); es el escenario en el que tiene lugar un debate entre la acusación promovida por órganos de la comunidad política y un individuo habitante y ciudadano de esa comunidad. Si la garantía de la existencia de un debate es una condición para que una comunidad democrática pueda llamar a rendir cuentas a un ciudadano, la suspensión del juicio -entendida como suspensión del debatepodría traer consigo el efecto de horadar o limitar el marco cuya existencia presupone la legitimidad de las decisiones de la justicia penal. Por lo tanto, admitir la suspensión de ese espacio público, a partir de consideraciones sólo analizadas desde los intereses del imputado, lacera un espacio de diálogo entre el presunto autor de una ofensa pública ${ }^{16}$ (Duff, 2015a y 2015b) y la comunidad. Desaparecería así ese espacio concreto en el que se despliega una actividad colectiva de aplicación de normas que pertenecen a todos y que se comprenden en el marco de una cierta manera de entender valores compartidos (Roth, 2015).

En tercer lugar, considerar la suspensión del juicio a prueba como un derecho del imputado de evitar el juicio, que sería per se negativo, produce una suerte de privatización inversa del proceso: ya no sería el acusador privado quien llevaría adelante la acusación pese a la oposición firme del Estado, sino sería el propio imputado el que privaría a la comunidad del juicio.

Por otra parte, garantizar un foro para rendir cuentas no debe entenderse como sinónimo de declararse culpable o ser condenado; sólo implica que el sospechado de cometer un delito es un agente moral y como tal se encuentra capacitado para dar sus razones ante sus

\footnotetext{
${ }^{16}$ En el sentido de una ofensa que afecta a la víctima concreta del hecho pero también a todos nosotros, como comunidad, al haber lesionado el autor los derechos básicos que nos reconocemos y debemos mutuamente.
} 
Grbavac,H.D.Democracia deliberativa y suspensión del juicio a prueba: una reflexión sobre sus posibles conexiones. Derecho y Ciencias Sociales. Octubre 2018. No Pgs 75-92 ISNN 1852-2971. Instituto de Cultura Jurídica

iguales. Aquél se encuentra enlazado a la comunidad en la que vive por un conjunto de deberes correlativos a todos los derechos que ha podido ejercer gracias al aporte de esa comunidad $^{17}$ (v. gr, a través de una educación y salud gratuita, del acceso a una vivienda digna, etc.). Esos derechos bien pueden justificar ciertos deberes ${ }^{18}$ para con la comunidad (que garantiza, asimismo, el sistema democrático-republicano de gobierno que reconoce aquellos derechos), uno de los cuales puede ser el de estar disponible ${ }^{19}$ para brindar sus razones cuando la sociedad sospeche que aquél ha cometido un delito. La suspensión del juicio a prueba, por el contrario, asegura que aquél no se encuentre disponible ${ }^{20}$.

A partir de una concepción como la ofrecida, podría resolverse la controversia acerca de si la suspensión del juicio a prueba se encuentra actualmente excluida en los delitos que sólo tienen como sanción la pena de inhabilitación o si también se extiende a las ofensas que tienen la pena de inhabilitación como pena conjunta ${ }^{21}$. A favor de la tesis restrictiva, podría decirse que la pena de inhabilitación conjunta, con la que se encuentran conminados los delitos culposos, pretende capturar la idea de que el acusado de haber cometido un delito en el marco de una actividad reglada ${ }^{22}$ (v. gr., la actividad médica, la conducción de vehículos automotores) tiene un deber especial para con la comunidad que lo autorizó a

\footnotetext{
${ }^{17}$ Distinto es el caso cuando no se encuentran presentes, en lenguaje de Duff, las "precondiciones de la responsabilidad penal", esto es, cuando el acusado ha sido sistemáticamente maltratado o excluido de las ventajas de la ciudadanía en el marco de sociedades notoriamente desiguales; en los supuestos en que la acusación es discriminatoria; o en los casos en que el Estado ha perdido la autoridad moral para llamar a rendir cuentas a un ciudadano en un proceso penal (Duff, 2015a; Gargarella, 2008 y 2016). En estos casos, y por tales razones, el Estado no tiene legitimidad para exigirle a los individuos que rindan cuentas en un juicio penal.

${ }^{18}$ Nino, refiriéndose a la justificación del voto obligatorio: "un gobierno democrático es un bien público. Como tal, no es justo disfrutar de sus beneficios como free-rider" (Nino, 2003 [1997]: 215).

19 Aquí puede encontrarse también una justificación para la coerción ejercida por el Estado contra un imputado que, se presume, puede fugarse. En contra de cierta opinión extendida, creemos que la máxima "afianzar la justicia" contenida en el Preámbulo de la Constitución argentina no permite aprehender en su totalidad esta idea. Desde nuestro punto de vista, el citado objetivo constitucional (desconectado por completo de la idea de que existe un lazo con la comunidad del que emergen derechos y obligaciones), al no ser incompatible con el juicio penal en rebeldía, podría no justificar la privación de la libertad de los individuos imputados que, se sospecha, puedan darse a la fuga. Véase una concepción "relacional" de la responsabilidad penal en Duff (2015a y 2015b).

${ }^{20} \mathrm{Si}$ se entendiera, por el contrario, a la suspensión del juicio a prueba como un derecho del imputado, no haría falta garantizar ningún espacio público de debate.

${ }^{21}$ Esta última interpretación fue aceptada por la Corte Suprema en el precedente "Gregorchuk" (CSJN, Fallos: 325:3229, 3/12/2002), apelando a la (presunta) intención del legislador y remitiendo a los fundamentos brindados por la Cámara Nacional de Casación Penal en el Fallo Plenario "Kosuta" (17/8/1999). En esta última sentencia, la mayoría de la Cámara recordó, además, que sólo la pena de prisión puede dejarse en suspenso, de lo que se derivaría la imposibilidad de aplicar el beneficio para las figuras que son castigadas con pena de prisión y de inhabilitación. En tanto, la primera interpretación, podría entenderse, es la defendida actualmente por la Corte a partir de "Norverto" (CSJN, N. 326. XLI. RHE, 23/4/2008) remitiendo "en lo pertinente" al precedente "Acosta" (CSJN, Fallos, 331:858, 23/4/2008), en el que se afirmó que ante dos interpretaciones en pugna siempre debe acudirse a la que resulte más favorable al reo.

${ }^{22}$ Lo que a su vez exigiría introducir una distinción en los delitos culposos entre aquéllos en los que la violación objetiva de un deber de cuidado recae sobre una actividad reglada, de los supuestos en los que la actividad no lo está. Véase lo que decimos al respecto en el texto.
} 
Grbavac,H.D.Democracia deliberativa y suspensión del juicio a prueba: una reflexión sobre sus posibles conexiones. Derecho y Ciencias Sociales. Octubre 2018. No Pgs 75-92 ISNN 1852-2971. Instituto de Cultura Jurídica

realizar aquélla. Ergo, cuando la comunidad lo llama a rendir cuentas, debe acudir y brindar sus razones en el juicio. Beneficiarse de ciertas actividades que requieren una autorización (administrativa) previa trae consigo el deber de responder por las consecuencias ocasionadas por la presunta realización defectuosa de aquéllas. Esto último no se satisface con el mero ofrecimiento de una "auto-inhabilitación" que bien puede interpretarse como un intento por eludir aquel deber de responder ${ }^{23}$. Esta tesis, a su vez, se adecuaría al texto del art. 76 bis anteúltimo párrafo, que alude a "los delitos reprimidos con pena de inhabilitación", sin distinguir si se trata de ofensas que tienen prevista esa sanción en forma exclusiva o de manera alternativa o conjunta.

Sin embargo, un partidario de la tesis amplia podría decir que así se impediría la aplicación del instituto para los hechos en los que no podría aplicarse la pena de inhabilitación (v. gr., en los delitos imprudentes en los que la acción u omisión en cuestión no conforma una actividad reglada). No obstante, ello podría ser contestado, ya que aquel argumento se explicaría desde una interpretación particular de la expresión "delitos" del art. 76 bis anteúltimo párrafo. Por el contrario, ante la ambigüedad de la expresión "delito" (Nino, 2008a: [1969]), podría afirmarse que el texto legal se refiere a los hechos criminales que estuvieran sancionados con pena de inhabilitación en el caso concreto, lo que supone decir que se trataría de ilícitos cuya imprudencia se proyecta sobre una actividad reglada. "Delito" se emplearía así como sinónimo de "tipo penal" ${ }^{24}$ y no como equivalente de “conducta típica, antijurídica y culpable”. En ese marco, y a los fines de la interpretación del art. 76 bis anteúltimo párrafo, los "delitos (tipos) culposos" presentan características diferentes dependiendo de si la acción en cuestión debe juzgarse a la luz de una "actividad reglada" o "no reglada", alcanzando la exclusión del art. 76 bis anteúltimo párrafo sólo a los primeros.

Un partidario de la tesis amplia podría esgrimir un contraargumento afincado en la necesidad de utilizar la pena de prisión sólo excepcionalmente, como la ultima ratio -por sus efectos desocializantes-, lo que exigiría incluir la suspensión del juicio a prueba para todos los delitos culposos. Pero esta réplica también podría ser contestada afirmando que la negativa a la concesión del instituto para ciertos delitos culposos no necesariamente trae

\footnotetext{
${ }^{23}$ Recordemos que cuando se discute la concesión de la suspensión del juicio a prueba no se discute si el hecho existió y si éste fue ejecutado por el imputado.

${ }^{24}$ Así, v. gr., cuando Zaffaroni, Alagia \& Slokar comentan el art. 42 del Cód. Penal -que regula la tentativaafirman que "[1]a expresión delito del texto legal (...) no puede entenderse de otro modo que como realización de la tipicidad objetiva" (2005: 822).
} 
Grbavac,H.D.Democracia deliberativa y suspensión del juicio a prueba: una reflexión sobre sus posibles conexiones. Derecho y Ciencias Sociales. Octubre 2018. No Pgs 75-92 ISNN 1852-2971. Instituto de Cultura Jurídica

consigo la imposición efectiva de prisión (v. gr., los casos de condena condicional ${ }^{25}$. Ello permitiría distinguir la idea de "justicia" o de "no impunidad" del recurso a la "pena de prisión efectiva", avanzándose así en un sistema de sanciones más civilizado.

Finalmente, la suspensión del juicio a prueba, entendida como un derecho, contrasta con el lugar que actualmente se le reconoce a la víctima en el proceso penal. Es cierto que ello no tendría por qué ser un problema ya que podría considerarse que el alcance con el que hoy participa la víctima en el juicio presenta algunos inconvenientes. Pero lo que no se puede hacer es realizar dos afirmaciones que se excluyen entre sí: si el imputado tiene derecho a evitar el juicio, la víctima no puede tener un derecho autónomo a que continúe la acción penal; y si la víctima tiene un derecho a lograr la condena de quien resultara culpable, el juicio nunca puede suspenderse sin su consentimiento. La extensión que hoy se le reconoce al querellante para intervenir sólo se explica desde una concepción que considera que la víctima de un delito tiene, en cuanto tal, el derecho a lograr la condena del responsable de aquél ${ }^{26}$. Ello implica adoptar una teoría de la pena que visualiza al castigo como un imperativo que debe ser universalizado toda vez que una víctima lo exija y sin que puedan considerarse razones de utilidad para la comunidad. Pero adoptar esta tesis no se compadece con acudir a institutos como el de la suspensión del juicio a prueba que explícitamente permiten la suspensión de la acción penal ${ }^{27}$. Sin embargo, "la tesis del castigo obligatorio" ayuda a encubrir la selectividad propia del sistema penal (Zaffaroni, Alagia \& Slokar, 2005), al tiempo que, en ocasiones, impide su propia vigencia (v. gr., piénsese en los problemas que se derivarían para la estabilidad de gobiernos democráticos en transiciones post-dictatoriales). Por el contrario, sostener una teoría de la pena diferente permitiría entender que

Condenar a aquellos que han renunciado a su derecho a no ser condenados, no se debe a que se haya reconocido que sus víctimas o sus familiares tienen el derecho a

\footnotetext{
${ }^{25}$ No obstante, aquel argumento permitiría sostener la necesidad de una modificación legal que permita ampliar los supuestos de condenas sin prisión (v. gr., incorporando la probation anglosajona, los trabajos comunitarios como pena) y escindir la acción penal en tantas acciones como clases de pena de que se trate (v. gr., suspendiéndose el juicio sólo para una de esas penas (la pena de prisión) y continuando respecto a la pena de inhabilitación).

${ }^{26}$ En "Santillán" (CSJN, Fallos 321:2021, 13/8/1998), en el que se dejó sentado que el querellante al fundar el pedido de pena contra el acusado ejerce su derecho a la defensa en juicio (Constitución argentina, arts. 18 y 75 inc. 22; Convención Americana de Derechos Humanos art. 8. 1; y Pacto Internacional de Derechos Civiles y Políticos, art. 14 1). En tanto, en “Góngora" (CSJN, Fallos: 336:392, 23/4/2013) se afirmó que la víctima tiene derecho a que se realice el juicio, entendido éste como Plenario.

${ }^{27}$ Obsérvese la contradicción actual entre, por una parte, las facultades que se le reconocen a la víctima desde el precedente "Santillán" (CSJN, Fallos 321:2021, 13/8/1998) y la impotencia, por otro lado, que tiene la víctima para bloquear -en muchos casos- la concesión de la suspensión del juicio a prueba.
} 
Grbavac,H.D.Democracia deliberativa y suspensión del juicio a prueba: una reflexión sobre sus posibles conexiones. Derecho y Ciencias Sociales. Octubre 2018. No Pgs 75-92 ISNN 1852-2971. Instituto de Cultura Jurídica

que se lleve a cabo esa condena. Es la consecuencia de una meta colectiva impuesta por la política de proteger los derechos humanos hacia el futuro. De esta manera, nadie puede exigir que esa condena sea universalizada a casos similares si de ese modo no se va a lograr el objetivo de las condenas (...) Esto no quiere decir que la selección pueda ser completamente arbitraria (...) La selección se debe realizar según su utilidad para satisfacer las metas que se buscan dentro de criterios generalmente permitidos (Nino, 2015 [1990]: 318) . $^{28}$.

\section{3. La posible conexión entre la suspensión del juicio a prueba y un Derecho Penal}

\section{deliberativo.}

La tesis expuesta podría ser cuestionada diciendo que no considerar a la suspensión del juicio a prueba como un derecho del imputado, garantizaría la arbitrariedad de los órganos del Estado al tiempo de su concesión. Sin embargo, este temor deriva de creer que toda valoración moral realizada judicialmente es sinónimo de arbitrariedad o sinrazón. Por el contrario y tal como lo demostró Nino (1989 [1974), no explicitar los presupuestos valorativos presentes en toda decisión judicial es lo que facilita la arbitrariedad de los operadores del sistema, ya que permite encubrir (del debate y del control de las partes) las verdaderas razones de la decisión.

Por otra parte, cuando se analiza conceder (o no) la suspensión del juicio a prueba no se discute si el imputado cometió el hecho o si éste existió realmente. Sólo se reflexiona acerca de si podría suspenderse un juicio de cuya terminación podría derivarse una pena. Por tanto, tales consideraciones deben relacionarse con los presupuestos que tienen que estar presentes a la hora de determinar si el castigo penal debe aplicarse. En otras palabras, la discusión sobre la aplicación de una pena ${ }^{29}$ está sujeta a una serie de consideraciones (las razones de la pena) que deben estar presentes, con independencia de la comisión de un delito. En ese marco, ¿cómo podría entenderse entonces la suspensión del juicio a prueba en el contexto de un Derecho Penal deliberativo? Una posible respuesta es concebirla como una herramienta o mecanismo del que dispone la comunidad política para enfrentar

\footnotetext{
${ }^{28}$ No afirmamos que la víctima deba ser excluida del proceso penal; antes bien, ella juega un rol fundamental, en primer lugar, para que se active un proceso criminal. Además, su intervención es muy importante ya que nadie mejor que ella -en tanto la protagonista lamentable del suceso- para colaborar con la fiscalía a efectos de la investigación. Por otra parte, la constitución como parte de los ciudadanos en los delitos de corrupción, v. gr., podría ser importante ante la burocracia o el desinterés de los órganos del Estado en investigar tales hechos. Sin embargo, lo que sí afirmamos es que la víctima no debería tener la posibilidad de convertir la acción pública en acción privada (como lo permiten varios códigos procesales provinciales argentinos) ni permitir la apertura del debate cuando mediare oposición de la fiscalía y la misma se encuentre ratificada por una instancia judicial ni tampoco participar de manera autónoma junto a la fiscalía en el Plenario.

${ }^{29}$ Por fuera de los casos en que un individuo es inocente, en los que siempre se lesionaría el principio de inviolabilidad persona (Nino, 2007 [1989]).
} 
Grbavac,H.D.Democracia deliberativa y suspensión del juicio a prueba: una reflexión sobre sus posibles conexiones. Derecho y Ciencias Sociales. Octubre 2018. N Pgs 75-92 ISNN 1852-2971. Instituto de Cultura Jurídica

la impunidad y equilibrar la desigual aplicación de la ley penal contra los sectores más desaventajados. Serviría, en términos de Braithwaite y Pettit, un “objetivo” (2015 [1990]: cap. 2) o, en lenguaje de Dworkin, una "política pública" (1993 [1977]) gobernada por ciertos criterios dirigidos a contrarrestar la selectividad del Derecho Penal, direccionando los (siempre) insuficientes recursos estatales contra los delitos de mayor gravedad o contra los casos que profundizan el sentimiento de impunidad en la comunidad. Asimismo podría servir como una especie de correctivo que permitiría la suspensión del juicio cuando no se encuentran presentes "las precondiciones de la responsabilidad penal" (Duff, 2015a y 2015b), bloqueando, para un caso particular, la legitimidad que, en cuanto principio general, ostenta un Estado Democrático para sancionar a sus ciudadanos ${ }^{30}$.

Sin embargo, podría tratar de refutarse este argumento afirmándose que no tendría sentido dejar librada la aplicación del instituto a la voluntad del imputado. Si el Estado no cuenta con la legitimidad para penar a ese individuo en concreto o si ha decidido, v. gr., suspender la persecución penal por motivos fundados en razones de prevención general, sería contraintuitivo que ello dependa de la solicitud del imputado. No obstante, la exigencia de que el acusado requiera la suspensión del juicio a prueba podría maximizar los presupuestos deliberativos de un juicio, fomentando un diálogo entre aquél y la comunidad representada a través de las autoridades judiciales. Sería un caso especial de aplicación del principio de oportunidad procesal en el que, a diferencia de los casos tradicionales, no bastaría sólo con la voluntad del fiscal para la suspensión de la acción penal.

Podría incluso apelarse aquí a la teoría de las "fallas del proceso" (Estlund, 2011 [2008]: cap. 10). Estlund, basándose en consideraciones de Marcuse, se refiere a ciertas actividades realizadas en nuestras democracias reales y que podrían ser censuradas desde el modelo deliberativo ideal. Sin embargo, como las democracias reales distan mucho de garantizar, por razones de fuerza, poder, riqueza o influencia, que todos los ciudadanos se encuentren en igualdad de condiciones para debatir con otros -logrando así que la decisión política adoptada contemple las necesidades de todas las partes eventualmente afectadas por el tema de discusión- es legítimo reconocer la incorporación de "actos disruptores". Estos actos, que no podrían justificarse desde el ideal deliberativo pero que inscriptos en un contexto en los que existe una situación de desigualdad previa que afecta a aquel ideal,

\footnotetext{
${ }^{30}$ En contra de considerar que un Estado, aún el Estado Democrático, tiene legitimidad para hacer uso de su aparato punitivo, véase la llamada "teoría agnóstica de la pena" (Zaffaroni, Alagia y Slokar: 2005: cap. 2). Por el contrario, considerando que los aportes de la crimonología crítica no deberían llevar a una deslegitimación total del Estado democrático para penar a sus ciudadanos, debiendo sólo impedir la aplicación de penas ante casos concretos, véase Nino (1992, 2008b y 2008c).
} 
Grbavac,H.D.Democracia deliberativa y suspensión del juicio a prueba: una reflexión sobre sus posibles conexiones. Derecho y Ciencias Sociales. Octubre 2018. N Pgs 75-92 ISNN 1852-2971. Instituto de Cultura Jurídica

cumplen una función de contrapeso que disminuiría o neutralizaría esa desigualdad real que opera sobre el marco deliberativo real.

La actividad disruptiva (para nuestro caso, la suspensión del juicio a prueba) maximizaría el proceso deliberativo real, entendido éste como el medio más idóneo para acceder al conocimiento de la decisión más cercana al ideal de justicia ${ }^{31}$. La selectividad del sistema penal operaría como el factor de desigualdad en la aplicación igualitaria de la ley penal, mientras que la suspensión del juicio a prueba actuaría como el acto disruptor que analizado en términos ideales- lesionaría el principio de igualdad al introducir supuestos en los que deliberadamente puede suspenderse y extinguirse la acción penal. Sin embargo, la suspensión promovería una aplicación más igualitaria de la ley penal, que ya no estaría dirigida contra los sujetos más desfavorecidos o ante los casos menos graves, sino contra los sectores habitualmente inmunes a la aplicación del castigo, contra los delitos de mayor envergadura, contra quienes ejercen una situación específica de dominación en perjuicio de miembros de colectivos discriminados o denigrados. Sobre esto último, podría argumentarse para impedir bloquear la suspensión del juicio a prueba cuando se trata de delitos cometidos en contextos de violencia de género.

Al mismo tiempo podrían agregarse razones vinculadas a la finalidad de la sanción penal para la procedencia de la suspensión del juicio. Así el instituto también operaría cuando, pese al cumplimiento de las precondiciones referidas, la aplicación del eventual castigo sería contraintuitiva a las razones por las cuales un Derecho Penal deliberativo sanciona a sus ciudadanos. Por lo tanto, el instituto debería aplicarse cuando la pena que se impondría no se adecúe a las razones que legitiman al Estado a hacer uso de ella.

Un Derecho Penal democrático-deliberativo se caracteriza por concebir a las personas como agentes morales capaces de deliberar, dar y actuar conforme a razones morales y capaces de sostener y cambiar sus puntos de vista a partir de la discusión pública (Duff 2015a y 2015b; Gargarella, 2008 y 2016; Nino, 2003 [1997]). Por lo tanto, la pena de prisión debe utilizarse excepcionalmente y sólo para casos muy graves, "aquellos que nos fuerzan a decir que, durante un tiempo, no podemos vivir en comunidad cívica normal con el delincuente" (Duff, 2015a: 63), ya que es evidente que la cárcel excluye al preso de las facultades de la vida cívica normal. Así, el principio general de la sanción penal ya no sería excluyente (la prisión no sería la "regla") buscando, por el contrario, afianzar su aspecto

\footnotetext{
${ }^{31}$ Véase en Estlund (2011 [2008]) y Nino (2003 [1997] y 2007 [1989]) dos justificaciones de la concepción deliberativa de la democracia en el marco del reconocimiento a la existencia de un "objetivismo moral" a cuyo conocimiento podría accederse a partir de las virtudes epistémicas del procedimiento democrático de toma de decisiones.
} 
Grbavac,H.D.Democracia deliberativa y suspensión del juicio a prueba: una reflexión sobre sus posibles conexiones. Derecho y Ciencias Sociales. Octubre 2018. N Pgs 75-92 ISNN 1852-2971. Instituto de Cultura Jurídica

comunicativo, maximizando la posibilidad de un diálogo real entre todas las personas $\operatorname{afectadas}^{32}$.

Por el contrario, muchas de las respuestas que habitualmente brinda nuestra justicia penal parten de un "enfoque equivocado", determinado por "la naturaleza radicalmente individualista de nuestro derecho, y de nuestro derecho penal en particular", siendo parte del problema "el carácter "adversarial” de nuestros juicios penales (Gargarella, 2008: 247). Este esquema

nos dice que, ante cada crimen o violación de derechos, no estamos dispuestos a hacernos las preguntas más fundamentales sobre las condiciones sociales del delito (¿qué hemos hechos para merecer esto?, ¿qué para generar este tipo de criminalidad?); sobre las responsabilidades derivadas de las reglas que nos organizan (¿en qué situación dejamos a los miembros más desaventajados de la sociedad?, ¿ayudan nuestras instituciones a promover la solidaridad o el egoísmo?, ¿son ellas más favorables a generar comportamientos cooperativos o de explotación?); sobre las responsabilidades propias de aquellos que aplican u omiten poner en práctica nuestros pactos más básicos (¿están nuestros legisladores llevando a cabo los compromisos sociales de la Constitución?, ¿se encuentran nuestros jueces poniendo en marcha los derechos de tipo económico incorporados en aquel texto?); sobre el peculiar diseño político que organiza nuestra vida en común (¿resultan nuestras instituciones más sensibles a las demandas populares o a la demanda de una minoría de lobbistas (...) ?, ¿por qué razones?). Enfrentamos al acusador con el acusado como si el mundo se redujera a dos personas, como si el delito en cuestión los involucrara a ellos y sólo a ellos, como si se tratara de un asunto del que somos ajenos (Gargarella, 2008: 247-248).

En esa línea, la excepcionalidad de la prisión no podría ser dejada de lado apelando al consentimiento del sujeto, ya que ello no sólo implicaría la adopción de una teoría retributiva de la pena (con los problemas que han sido referidos) sino que, además, permitiría la imposición de sanciones draconianas que excluirían al infractor del proceso de deliberación, adoptándose medidas incompatibles con la fuerza epistémica de la democracia, al legitimarse una decisión (v. gr., la imposición de la pena de muerte o de la prisión perpetua sin libertad condicional) que excluiría al sujeto condenado de la

\footnotetext{
${ }^{32}$ Véase al respecto Braithwaite \& Pettit (2015 [1990]), Duff (2015a y 2015b) y Gargarella (2008 y 2016).
} 
Grbavac,H.D.Democracia deliberativa y suspensión del juicio a prueba: una reflexión sobre sus posibles conexiones. Derecho y Ciencias Sociales. Octubre 2018. No Pgs 75-92 ISNN 1852-2971. Instituto de Cultura Jurídica

deliberación pública, y que, por consiguiente, atentaría contra la característica de imparcialidad de tales medidas (Nino, 2003 [1997]). Por ello, y como principio general, debería echarse mano de la prisión efectiva sólo ante situaciones excepcionales, administrándose siempre de tal modo que se siga reconociendo a los detenidos como ciudadanos, es decir, respetándose sus facultades cívicas (v. gr., preservando su derecho al voto, reconociéndoles privacidad dentro de la cárcel y la posibilidad de seguir manteniendo contacto frecuente con personas que no están detenidas [Duff, 2015a], dotando de amplias facultades a un ombudsman de los detenidos que vele por sus derechos, asegurándoles que no sufrirán la imposición de malos tratos). Esto último, a su vez, debería generar una actitud de compromiso mucho más activa con esta tarea de parte del Poder Judicial, sobre todo si se repara en la enorme distancia entre el estado actual de nuestras prisiones y las previsiones del art. 18 de la Const. Nacional ${ }^{33}$.

Al implicar el encarcelamiento la imposición intencional de un sufrimiento a un sujeto por parte del Estado (Hart, 1968), es difícil la justificación de dicha práctica en una comunidad democrática (Gargarella, 2008 y 2016) ${ }^{34}$. Ergo, es otra razón en favor de la excepcionalidad de la prisión.

En consecuencia, un Derecho Penal deliberativo debería sólo aplicar la pena de prisión efectiva para casos muy graves ${ }^{35}$ y bajo las limitaciones referidas. La pena, en este paradigma, sólo puede perseguir maximizar un debate entre los miembros de la comunidad política de que la comisión de ciertos delitos que afectan, v. gr., los derechos fundamentales de las personas, habilitan de parte de la misma comunidad una actitud de compromiso, respeto y compasión hacia las víctimas de aquéllos. Como consecuencia de este reconocimiento, que se vería frustrado si las autoridades ante la comisión de delitos graves guardasen una actitud de pasividad, complicidad o no reconocimiento a la víctima

\footnotetext{
${ }^{33}$ Véase, p. ej., el Boletín Estadístico de la Procuración Penitenciaria de la Nación (Primer trimestre 2016): "Las cárceles federales en números", Año 1 N ${ }^{\circ} 2$ Recuperado el 17/7/2016 de: http://ppn.gov.ar/?q=node/2586. Consúltese también "El lado más oculto de las cárceles", 17/7/2016. Recuperado el 23/6/2017 de: http://www.lanacion.com.ar/1909334-cucarachas-basura-hacinamiento-ytorturas-el-lado-mas-oscuro-de-las-carceles-argentinas; y "Las 40 fotos que muestran las condiciones inhumanas en las cárceles de Olmos y Marcos Paz", 15/7/2016. Recuperado el 23/6/2017 de: http://www.infobae.com/sociedad/2016/07/15/las-40-fotos-que-muestran-las-condiciones-inhumanas-en-lascarceles-de-olmos-y-marcos-pazl.

${ }^{34}$ El culpable sigue siendo miembro de la comunidad política que lo ha sancionado; por lo tanto, sigue gozando de los derechos y garantías reconocidos por la Constitución del Estado democrático. Lo contrario, implicaría adoptar la tesis, moralmente inaceptable, de Rousseau (2003 [1762]) de que todo delincuente, al romper el pacto social, se convierte en un traidor a la patria quedando, en consecuencia, excluido de ella. Sin embargo, no debe olvidarse que la sentencia de Rousseau sólo se refería a los casos de sociedades donde se había plasmado "la voluntad general", es decir, sociedades igualitarias en las que se había impuesto el autogobierno colectivo. En otras palabras, no podría válidamente acudirse a Rousseau para justificar el castigo en el contexto de nuestras sociedades actuales.

${ }^{35}$ Véase, v. gr., el "principio de parsimonia" defendido por Braithwaite y Pettit (2015 [1990]).
} 
Grbavac,H.D.Democracia deliberativa y suspensión del juicio a prueba: una reflexión sobre sus posibles conexiones. Derecho y Ciencias Sociales. Octubre 2018. N Pgs 75-92 ISNN 1852-2971. Instituto de Cultura Jurídica

en cuanto tal (Malamud Goti, 2008 y 2016) ${ }^{36}$, el Estado puede hacer uso de la pena de prisión efectiva.

\section{Conclusión.-}

Con el presente trabajo abordamos el instituto de la suspensión del juicio a prueba desde los presupuestos de la democracia deliberativa. Analizamos las implicancias que se derivarían para esta figura desde esta concepción y cuestionamos las interpretaciones que consideran que la suspensión del juicio a prueba es un derecho del imputado. En este marco, afirmamos que aquélla puede ser concebida como un mecanismo con el que la comunidad política puede maximizar el diálogo entre sus integrantes "puertas adentro" de un juicio criminal, disminuyendo la selectividad del Derecho Penal. Esta tesis permite reflexionar sobre el posible régimen de la acción penal en un Derecho Penal deliberativo, comprometido con la maximización del diálogo y la comunicación entre todas las partes involucradas (la víctima, el posible ofensor y la comunidad) como medio para promover la integración social de sus miembros y reducción de los niveles de castigo.

Esta interpretación, finalmente, genera consecuencias concretas en el modo en que entendemos las controversias planteadas a partir de la redacción del art. 76 bis del Código Penal. Así, una visión deliberativa del Derecho Penal tiene mucho que decir sobre el modo en que entendemos: i) la facultad que tienen los jueces ante una solicitud presentada por un imputado para acceder al beneficio; ii) la relevancia que tendría la oposición de la víctima ante aquella solicitud; iii) el modo en que interpretamos la exclusión de la figura cuando se trata de delitos reprimidos con pena de inhabilitación; y iv) la influencia de ciertos tratados internacionales suscriptos por el Estado argentino para la aplicación (o no) de la suspensión del juicio a prueba.

\section{Bibliografía.-}

Arocena, G. A. (2010). Impedimento de contacto de menores con sus padres no convivientes. Buenos Aires: Astrea.

Bovino, A. (2006). La suspensión del procedimiento penal prueba en el Código Penal argentino. Buenos Aires: Editores del Puerto.

\footnotetext{
${ }^{36}$ Malamud Goti (2008 y 2016) ha puntualizado cómo la pena tiene la función de devolverle a la víctima y a sus familiares el status o la dignidad de persona, que les fuera arrebatado por el delito y el delincuente.
} 
Grbavac,H.D.Democracia deliberativa y suspensión del juicio a prueba: una reflexión sobre sus posibles conexiones. Derecho y Ciencias Sociales. Octubre 2018. N Pgs 75-92 ISNN 1852-2971. Instituto de Cultura Jurídica

Braithwaite, J. y Pettit, P. (2015 [1990]). No sólo su merecido. Por una justicia penal que vaya más allá del castigo. E. Odriozola (trad.). Buenos Aires: Siglo XXI editores.

CSJN, “Acosta, Alejandro Esteban s/ infracción art. 14, 1 párrafo ley 23.737”, Fallos: $331: 858,23 / 4 / 2008$

CSJN, "Norverto, Jorge Braulio s/ infracción artículo 302 del C. P.”, N. 326. XLI. RHE, 23/4/2008.

CSJN, “Padula, Osvaldo Rafael y otros s/ defraudación”, Fallos, 320:2451, 11/11/1997.

Duff, A. (2015a). Sobre el castigo. Por una justicia penal que hable el lenguaje de la comunidad. H. Pons, I. Noel y J. Vecchione (trads.). Buenos Aires: Siglo XXI Editores.

Duff, A. (2015b). “Autoridad y responsabilidad en Derecho penal internacional”. LADI, Revista Latinoamericana de Derecho Internacional (2), mayo de 2015. Recuperado el 26/5/2017 de www.revistaladi.com.ar/numero2-duff/

Dworkin, R. (1993 [1977]). Los derechos en serio. M. Guastavino (trad.). Barcelona: Planeta- De Agostini, S. A.

Estlund, D. (2011 [2008]). La autoridad democrática. Los fundamentos de las decisiones políticas legítimas. S. Linares (trad.). Buenos Aires: Siglo XXI Editores.

Gargarella, R. (2016). Castigar al prójimo. Por una refundación democrática del Derecho Penal. Buenos Aires: Siglo XXI Editores.

Gargarella, R (2008). De la injusticia penal a la justicia social. Bogotá: Siglo del Hombre Editores - Facultad de Derecho Universidad de los Andes.

Hart, H. L. A. (1968). Punishment and Responsability. Essays in the Philosophy of Law. Oxford: Oxford University Press.

Kafka, F. (1967 [1925]). El Proceso. $3^{\text {a }}$ ed. La Habana: Instituto del Libro.

Malamud Goti, J. (2016). Crímenes de Estado. Dilemas de la Justicia. Buenos Aires: Hammurabi.

Malamud Goti, J. (2008). Suerte, moralidad y responsabilidad penal. Buenos Aires: Hammurabi.

Molero, M. A. (1998). “'Probation' y juicio abreviado. Cuando los cambios vienen marchando". Revista Jurídica Argentina La Ley 1998-D. Buenos Aires: La Ley, pp. 1347-1353.

Molero, M. A. \& Grbavac, H. D. (2013). Código Procesal Penal de la Provincia del Chaco. Comentario a los artículos de la reforma según ley $N^{\circ} 7143$. Desarrollo doctrinario y esquemas procesales. Resistencia: ConTexto. 
Nino, C. S. (2015 [1991]). "El deber de castigar los abusos cometidos en el pasado contra los derechos humanos puesto en contexto. El caso de la Argentina". Juicio al mal absoluto. ¿Hasta dónde debe llegar la justicia retroactiva en casos de violaciones masivas de los derechos humanos? G. Maurino (ed.). Buenos Aires: Siglo XXI editores.

Nino, C. S. (2013). Ocho lecciones sobre ética y derecho para pensar la democracia (cap. 8). Buenos Aires: Siglo XXI editores.

Nino, C. S. (2008a [1969]). "La definición de 'delito"”. Los Escritos de Carlos S. Nino (vol. 3): Fundamentos de Derecho Penal. G. Maurino (ed.). Buenos Aires: Gedisa, pp. 187-204.

Nino, C. S. (2008b [1991]). "La huida frente a las penas". Los Escritos de Carlos S. Nino (vol. 3): Fundamentos de Derecho Penal. G. Maurino (ed.). Buenos Aires: Gedisa, pp. 137-150.

Nino, C. S. (2008c [1992]). "Respuesta a Zaffaroni”. Los Escritos de Carlos S. Nino (vol. 3): Fundamentos de Derecho Penal. G. Maurino (ed.). Buenos Aires: Gedisa, pp. 151-154.

Nino, C. S. (2007 [1989]). Ética y derechos humanos. Un ensayo de fundamentación. $2^{\mathrm{a}}$ ed. Buenos Aires: Astrea.

Nino, C. S. (2003 [1997]). La constitución de la democracia deliberativa. R. P. Saba (trad.). Barcelona: Gedisa.

Nino, C. S. (1992). Un país al margen de la ley. Estudio de la anomia como componente del subdesarrollo argentino. Buenos Aires: Emecé editores.

Nino, C. S. (1989 [1974]). Consideraciones sobre la dogmática jurídica (con referencia particular a la dogmática penal). México: UNAM:

Roth, L. (2015). "El derecho penal de una comunidad democrática”. En Duff, A. (2015), Sobre el castigo. Por una justicia penal que hable el lenguaje de la comunidad, pp. 13-23. Buenos Aires: Siglo XXI editores, pp. 13-23.

Zaffaroni, E. R., Alagia, A. \& Slokar, A. (2005). Derecho Penal Parte General $2^{\mathrm{a}}$ ed. Buenos Aires: Ediar. 